\title{
Retinopathy in pregnancy in women with type 1 diabetes - a study of associations with arterial wall elasticity and mutation in coagulation genes
}

\author{
Finn Friis Lauszus*, Poul Lange Gron, Ingvild Holm Tjessem, Hanine Fadel Mustafa Al-Far and Ole Winther Rasmussen \\ Department of Gynecology \& Obstetrics, Herning Hospital, Herning, Denmark
}

\begin{abstract}
Aim: The arterial wall elasticity and genetic setting is a potential risk factor for dysfunction of vas $\neg$ cular endothelial cells and the clinical expression of retinopathy The prevalence was evaluated of polymorphism in the genes of methylene-tetrahydro-folate-reductase (MTFHR), Factor V, glycoprotein IIb/IIIa (Gp2b3a), and

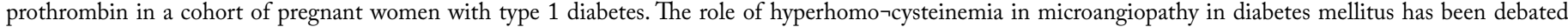
and is mainly seen with reduced activity of the MTHFR gene. The arterial resistance index (AASI) has been used to detect arterial dysfunction and correlate with cardiovascular morbidity and mortality in patients with hypertension.

Design: Two-hundred-and-thirty-three women with type 1 diabetes mellitus were analyzed for MTHFR gene polymorphism and Factor V Leiden. In 176 of these women AASI was further evaluated. In a sub-cohort of 40 women with preeclampsia, mutations in glycoprotein IIb/IIIa (Gp2b3a) and prothrombin was measured. The pregnancy and ophthalmological examination data charts were reviewed retrospectively.

Results: Retinopathy was associated with higher AASI during pregnancy ( $\mathrm{p}<0.01$, in all three trimesters) and preeclampsia ( $\mathrm{p}<0.05)$. The stiffness increased with higher grades of retinopathy. AASI in women with simplex and proliferative retinopathy followed different patterns during the three trimesters, even when adjusted for age, BMI, and glycemic regulation ( $\mathrm{p}<0.01)$. None of the studied coagulation genes (MTHFR, Factor V, Gp2b3a, and prothrombin) were found associated with retinopathy or preeclampsia.
\end{abstract}

Conclusion: Retinopathy showed a strong association with AASI during pregnancy and not outside pregnancy in women with type 1 diabetes. This suggests a pregnancy-related functional change in the vascular bed.

Abbreviations: MTFHR: Methylene-tetrahydro-folate-reductase; Glycoprotein IIb/IIIa: Gp2b3a; Factor II: Prothrombin

\section{Introduction}

Retinopathy is a common complication of pregnancy in type 1 diabetes mellitus and preterm delivery may be induced in proliferative retinopathy in order to save eye-sight $[1,2]$. Retinopathy has a complex pathogenesis including dysfunction of vascular endothelial cells and inherent genetic and growth factors; it may share common pathways with other vasculopathy i.e. albumin excretion rates. The arterial resistance index (AASI) has been used to detect arterial dysfunction and correlate with known microangiopathy and predict mortality in patients with hypertension. Pregnancy in a young population with known retinopathy seems to be suited to evaluate the use for AASI in predicting increased risk and assessing the vascular beds ability to adapt to superimposed morbidity like preeclampsia.

Other risk factors have been recognized, one of them is elevated level of homocysteine [3]. Increasing incidence of vasculopathy and preeclampsia in diabetes mellitus is associated with increased homocysteine level [4-6]. Accumulating evidence points at genetic factors in the genesis of preeclampsia and concurrent increased homocysteine plasma levels $[7,8]$. Supplementation with folic acid and vitamin B6 has been applied with some beneficial effect in pregnancy with a history of intrauterine growth restriction and preeclampsia [9].
A common polymorphism in methylene-tetrahydro-folate-reductase (MTFHR 677C>T, a C to $\mathrm{T}$ substitution at nucleotide 677, which converts alanine to a valine residue) has been identified as responsible for reduced MTHFR activity and increased plasma homocysteine $[10,11]$.

Factor V Leiden is a mutated form of human factor $\mathrm{V}$ that causes an increase in blood clotting. With this mutation, the anticoagulant protein secreted is inhibited, leading to an increased tendency to form dangerous, abnormal blood clots. Factor V Leiden is the most common hereditary hypercoagulability disorder amongst ethnic Europeans and linked with increased risk of preeclampsia, abortions, intrauterine growth restriction, placental abruption, and thrombosis [12-14].

Glycoprotein IIb/IIIa (Gp2b3a, also known as integrin $\alpha \mathrm{IIb} \beta 3$ ) is a complex found on platelets. It is a receptor for fibrinogen and von

Correspondence to: Finn Friis Lauszus, senior consultant, Department of Gynecology and Obstetrics, Herning Hospital, Gl. Landevej 61, DK-7400 Herning, Denmark, Tel: +45 7842 36 14; Fax: +45 7843 4636; E-mail: finlau@rm.dk

Key words: diabetes mellitus, pregnancy in diabetics, retinopathy, blood pressure monitoring, methylene tetra hydro folate reductase, factor $V$ leiden, ambulatory blood pressure monitoring

Received: January 17, 2017; Accepted: February 09, 2017; Published: February 11,2017 
Willebrand factor and aids platelet activation. The complex is formed via calcium-dependent association of Gp2b3a, a required step in normal platelet aggregation and endothelial adherence. Platelet activation leads to the change in the platelet $\mathrm{Gp} 2 \mathrm{~b} 3 \mathrm{a}$ receptor that induces binding to fibrinogen. Polymorphism in integrin has been linked to preeclampsia and abortions [15].

Prothrombin (coagulation Factor II) is proteolytically cleaved to form thrombin in the clotting process. Thrombin in turn acts as a protease that converts soluble fibrinogen into insoluble strands of fibrin that form part of a clot, as well as catalyzing many other coagulationrelated reactions. Prothrombin mutations increase the risk of ocular thrombosis and abortions [14].

In this study, we examined the elasticity of the vascular wall by AASI and the prevalence of several genetic factors in pregnant women with type 1 diabetes mellitus. The associated morbidity with vascular dysfunction observed during pregnancy, i.e. retinopathy and preeclampsia was evaluated on the assumptions that the dynamic changes in the stiffness of the arterial wall and genetics may lead to similar events and would depict the biological characteristics of vasculopathy during pregnancy.

\section{Material and methods}

Two-hundred-and-sixty-eight pregnant women with insulindependent diabetes mellitus were recruited from the maternity ward between 1992 and 1998. In 233 women, the gene for MTFHR was successfully analyzed. The women were scheduled for ophthalmologic examination before pregnancy, once in each trimester, and 4 months after birth. Before and after pregnancy 103 women (44\%) and 171 (73\%), respectively, had an ophthalmologic examination. All 233 women had at least three fundus examinations during pregnancy except from ten who had less than three. These ten women displayed no retinopathy. Fundus photography was only performed in $53 \%$ of the women.

During pregnancy, the women came for routine ambulatory visits every second week until week 32 and hereafter weekly. Twenty-fourhour urine was collected for measurement of albumin excretion rate at every visit. Consistent normoalbuminuria was defined as samples from more than 2 visits with an urinary albumin excretion rate $<30$ $\mathrm{mg}$, microalbuminuria as $30 \mathrm{mg}-299 \mathrm{mg}$, and macroalbuminuria $>299$ mg per 24 hours. All women but two were on frequent dose insulin (4-6 times daily) and glycemia was monitored by frequent home measurements using regularly calibrated home glucometers.

$\mathrm{BP}$ was measured using a portable oscillometry monitor providing more than 60 readings per person per $24 \mathrm{~h}$ (SpaceLab 90207, Redmond, WA, USA). The details on validation of monitors, the recommended clinical setting, and the timing during the day of BP are found on the British Hypertension Society's homepage at www.bhsoc.org [17]. The equipment was programmed for cuff insufflations every 20 minutes from 0600 to $2300 \mathrm{~h}$, and every hour during the night. At inclusion and after demonstration of equipment, three auscultatory BP were measured in the supine position. The average of these three auscultatory measurements was termed the clinical BP. All auscultatory measurements were recorded with use of a random zero sphygmomanometer (Hawksley, Lancing, U.K.). The women followed their normal physical and daily activities throughout pregnancy and the women stated whether the measurement of BP took place on a workday or not. The measurement of BP was performed in gestational week 13, 25, and 33 and three months post partum in women with T1DM and at week 18 and 33 in the non-diabetic women.

The regression slope of diastolic on systolic BP from unedited 24-h recordings was computed for each participant at every time point in pregnancy. AASI was defined as one minus the regression slope of diastolic BP on systolic BP from the diurnal recording [18]. The regression line for AASI was not forced through zero. Thus, the stiffer the arterial tree, the closer the regression slope approaches zero and AASI consequently approaches one (Figure 1).

Preeclampsia was defined as diastolic blood pressure of 90

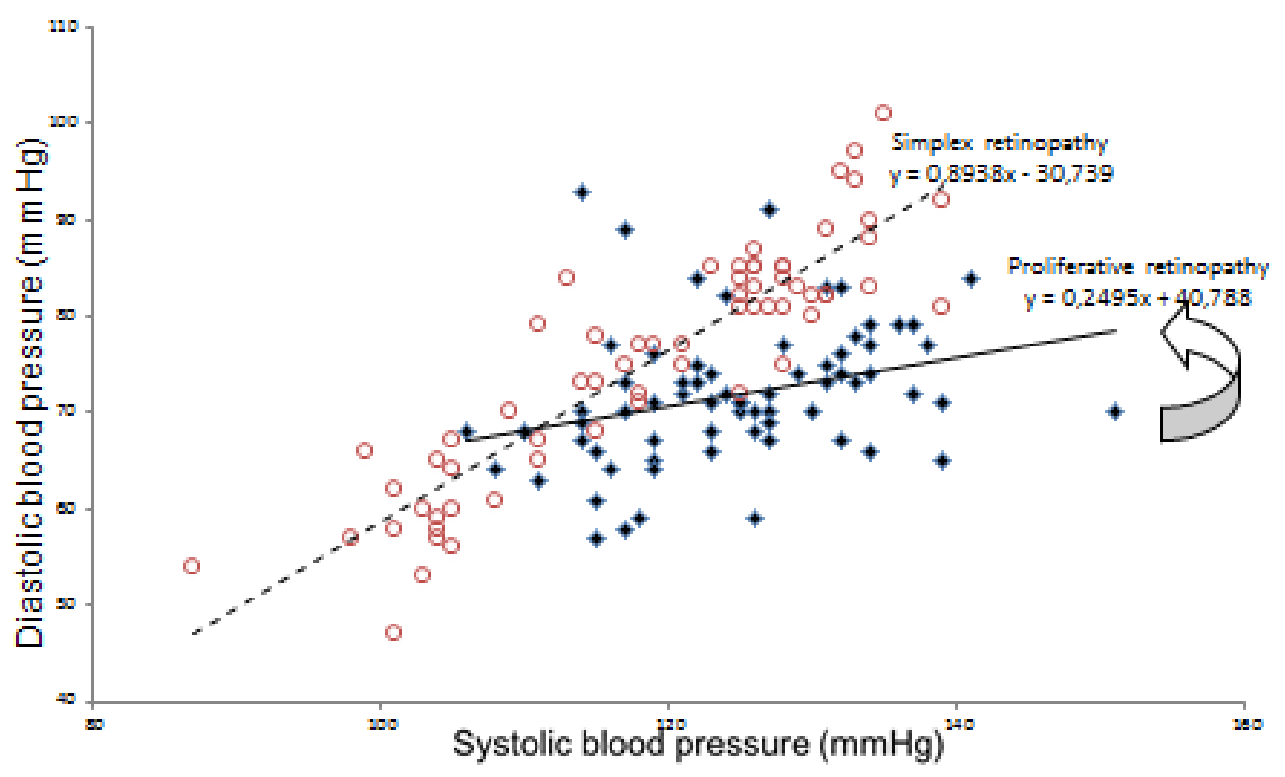

Red hollow circles: women with simplex retinopathy, mean 125/72, AASI=1-slope (interrupted line) $=1-0.89=0.11$

Blue filled diamonds: Woman with proliferative retinopathy mean blood pressure 119/75, AASI $=1$-slope (full line) $=1-0.25=0.75$. Arrow indicates the slope of blood pressure readings of the woman with proliferative retinopathy

Figure 1. Diurnal blood pressure readings from monitor in $3^{\text {rd }}$ trimester in two women with retinopathy. 
$\mathrm{mmHg}$ or greater and albuminuria in excess of $300 \mathrm{mg}$ in previously normo- and microalbuminuric women. In macroalbuminuric women preeclampsia was diagnosed when albumin excretion and uric acid increased significantly (three- and twofold, respectively). A birth weight ratio was computed by dividing the observed birth weight with the expected birth weight for the same gestational age and gender. The expected weights were calculated and distributed by the Danish Health and Medicines Authority based on the work of Marsál et al. [19].

The study was part of an evaluation of morbidity in diabetic pregnancy with respect to nephropathy and retinopathy approved by the local Ethical Committee (jr.nr.1992/2523, 1998/4147, and 2026-99) and by the Danish Data Protection Agency (no. 1-16-02-92-16) and all women gave their informed consent.

Genomic DNA was extracted from peripheral blood leukocytes from frozen samples, spotted on Whatman filter paper (Struers KEBO Lab. Rødovre, Denmark) and extracted according to the methods of Jinks et al. [20]. The MTHFR $677 \mathrm{C}>\mathrm{T}$ polymorphism was detected according to Frosst et al. [10]. Polymerase chain reaction was carried out in a volume of $25 \mu \mathrm{l}$. We used $3 \mu \mathrm{l}$ of the supernatant from the women blood spots as a polymerase chain reaction template. The methods of for detection of Factor V Leiden (1691G $\rightarrow$-A) and the prothrombin $20210 \mathrm{G} \rightarrow \mathrm{A}$ variant were performed according Gaustadnes et al. [21]. The background population consisted of samples drawn from Guthrie cards submitted to Statens Serum Institute, Copenhagen, in the cohort of children in Denmark [21]. The background population's incidence for MTHFR $(677 \mathrm{C} \rightarrow \mathrm{T})$, Factor V Leiden, and the prothrombin mutation 20210 was $50 \%(n=1084), 7 \%(n=4188)$, and $2 \%(n=500)$, respectively. Polymorphism in glycoprotein $2 \mathrm{~b} 3 \mathrm{a}$, the $\mathrm{Pl}^{\mathrm{A}}$ polymorphism, was detected by capillary electrophoresis following DNA extraction described by Miller et al. and O'Connor et al. [22,23]. In 40 women with preeclampsia (hereof 30 women with retinopathy) were chosen for analysis of the rare mutations in prothrombin and Gp2b3a as increased incidences in mutations are easier to detect if present in clinical meaningful numbers.

For MTFHR mutation the minimum sampling size was calculated to 186 subjects in each group (background $v s$. diabetes) if a difference of $10 \%$ was to be detected and 44 subjects if a difference of $20 \%$ was to be detected with a background frequency of heterozygosis of $42 \%$, a two-sided $p$-value $(\alpha)$ of 0.05 , and a power of $80(\beta=0.2)$.

\section{Statistical analysis}

Statistics was performed with IBM SPSS statistics 20. Difference between two means was tested with Student's t-test if data followed Gaussian distribution; otherwise Mann-Whitney's test was used. For evaluation of the contingency tables, Yates' test was used with correction for continuity in $2 \times 2$ tables, Fisher's test was used if any cell contained less than 6 persons. In $2 \times 3$ tables, Fisher's test for independence was performed assuming no direction of a trend. Then, if it showed $\mathrm{p}<0.05$, the table was tested with the $\chi^{2}$-test for trend. Comparison of the difference between means was tested with analysis of variance (ANOVA). Newman-Keul's post-hoc test was applied when the ANOVA test was $p<0.05$. Linear regression analysis was performed with AASI as dependent variable and retinopathy, preeclampsia, $\mathrm{HbAlc}$, age, and BMI as independent variables. Repeated measures analysis of variance (two-way-ANOVA) was used for comparison between groups during and after pregnancy and co-variants were added. A two-sided $\mathrm{p}<0.05$ was the level of significance. Values are given as mean $\pm \mathrm{SD}$, unless otherwise stated.

\section{Results}

Forty-one of 233 women (18\%) had microalbuminuria and 20 (9\%) macroalbuminuria during pregnancy. Ninety-two women (39\%) had simplex and twenty women (9\%) proliferative retinopathy. Sixty women (26\%) had preeclampsia and the incidence was associated with grade of retinopathy (Table $1, \mathrm{p}<0.04$ ). The incidence of preeclampsia rose with $100 \%$ when retinopathy was present (13 vs. $27 \%$, no retinopathy $v s$. present retinopathy, $\mathrm{p}<0.02)$. In women with normoalbuminuria this association was not found ( $15 v$ s. $23 \%, \mathrm{p}=0.29$ ). Retinopathy grade was found associated with $\mathrm{HbAlc}$ before, during and after pregnancy (Table 1 , all time points $\mathrm{p}<0.05$, data only shown for $1^{\text {st }}$ trimester)

The frequency of MTHFR polymorphism was similar in women with type 1 diabetes mellitus irrespective of the fundus status and preeclampsia (Table 2, retinopathy grade, $\mathrm{p}=0.77$; preeclampsia, $\mathrm{p}=1.0$ ). Heterozygosis was 52,51 , and $50 \%$ and homozygosis was 10,8 , and $5 \%$ for the women with no, simplex, and proliferative retinopathy, respectively. The incidence of heterozygosis in the background population was $42 \%$ and homozygosis was found in $8 \%$ (Table 2); thus, allele frequency of MTHFR polymorphism was calculated to $29 \%$. The women with type 1 diabetes mellitus had similar allele frequency of $28 \%$ based on the sample of 233 pregnant women ( $\mathrm{p}=0.78$, background $v s$. diabetic women, Pearson's $\chi^{2}$ - test). The genotypes were in perfect Hardy-Weinberg equilibrium. Similarly, the distribution of the Faktor $\mathrm{V}$ Leiden mutation was neither found associated with retinopathy grade $(\mathrm{p}=0.67)$ nor preeclampsia $(\mathrm{p}=0.7$, Table 3$)$. Its incidence was similar to the background population $(\mathrm{p}=0.21)$

In 176 of the above women AASI was evaluated and $47 \%$ of these women had simplex retinopathy and $9 \%$ had proliferative retinopathy; one woman lost her eye sight unilaterally despite laser treatment. Eleven percent displayed microalbuminuria and $13 \%$ microalbuminuria. AASI was higher during pregnancy in women with simplex and proliferative retinopathy; this was neither observed before nor after pregnancy (Table 1). Analysis with repeated measurements in $1^{\text {st }}, 2^{\text {nd }}$, and $3^{\text {rd }}$ trimester showed that AASI was significant associated with the grade of retinopathy and followed different patterns in women with

Table 1. $1^{\text {st }}$ trimester clinical and pregnancy data in 233 women with type 1 diabetes.

\begin{tabular}{|l|c|c|c|c|}
\hline & \multicolumn{3}{|c|}{ Retinopathy grade } & $\begin{array}{c}\text { All women with } \\
\text { type 1 diabetes }\end{array}$ \\
\hline No. & 121 & 92 & 20 & 233 \\
\hline Age (years) & $29 \pm 4$ & $28 \pm 5$ & $28 \pm 3$ & $28 \pm 4$ \\
\hline BMI $\left(\mathrm{kg} / \mathrm{m}^{2}\right)$ & $24 \pm 4$ & $25 \pm 4$ & $24 \pm 3$ & $24 \pm 4$ \\
\hline Duration of diabetes (years) & $7 \pm 6$ & $17 \pm 7$ & $20 \pm 6$ & $13 \pm 8 * *$ \\
\hline HbA1c (\%) & $7.0 \pm 1.1$ & $7.5 \pm 1.3$ & $8.1 \pm 1.2$ & $7.4 \pm 1.2 * *$ \\
\hline Creatinine clearance (ml/min) & $130 \pm 26$ & $129 \pm 30$ & $111 \pm 59$ & $128 \pm 32$ \\
\hline Diurnal sys BP (mmHg) $\S$ & $116 \pm 9$ & $121 \pm 9$ & $132 \pm 17$ & $120 \pm 11 * *$ \\
\hline Diurnal dia BP (mmHg) $\S$ & $69 \pm 6$ & $73 \pm 7$ & $82 \pm 11$ & $72 \pm 8 * *$ \\
\hline AASI pregravid $\S$ & $0.33 \pm 0.2$ & $0.28 \pm 0.18$ & $0.24 \pm 0.16$ & $0.28 \pm 0.18$ \\
\hline AASI 1st trimester $\S$ & $0.28 \pm 0.15$ & $0.32 \pm 0.15$ & $0.37 \pm 0.18 \#$ & $0.31 \pm 0.16^{* *}$ \\
\hline AASI 2nd trimester $\S$ & $0.27 \pm 0.13$ & $0.32 \pm 0.17$ & $0.37 \pm 0.2 \#$ & $0.3 \pm 0.16^{* *}$ \\
\hline AASI 3rd trimester $\S$ & $0.29 \pm 0.16$ & $0.35 \pm 0.17$ & $0.46 \pm 0.21 \#$ & $0.33 \pm 0.17 * *$ \\
\hline AASI 3 months post partum $\S$ & $0.26 \pm 0.18$ & $0.24 \pm 0.16$ & $0.21 \pm 0.16$ & $0.25 \pm 0.17$ \\
\hline Preeclampsia & $16(13 \%)$ & $26(28 \%)$ & $4(20 \%)$ & $46(20 \%)$ \\
\hline Birth weight (g) & $3784 \pm 716$ & $3377 \pm 749$ & $2538 \pm 1217 \#$ & $3510 \pm 886 * *$ \\
\hline Birth weight ratio a,b & $1.27 \pm 0.31$ & $1.28 \pm 0.27$ & $1.01 \pm 0.44 \#$ & $1.3 \pm 0.31 * *$ \\
\hline
\end{tabular}

$*: \mathrm{p}<0.05$ and $* *: \mathrm{p}<0.01$ test for difference between retinopathy grade (ANOVA); \# post hoc test: $\mathrm{p}<0.05$

$\S$ : data from subcohort of 176 women, pregravid: $n=34$, post partum $n=110$ 
simplex and proliferative retinopathy during the trimesters, also when adjusting for age, BMI, and glycemic regulation measured by $\mathrm{HbAlc}$ (Figure 2, $\mathrm{p}<0.001$ ). Regression confirmed that AASI was associated in all three trimester, also when adjusting for preeclampsia, age, BMI, and HbA1c $(\mathrm{p}<0.05)$.

In a sub-cohort of 40 of the 60 women with preeclampsia, mutation analysis for $\mathrm{Gp} 2 \mathrm{~b} 3 \mathrm{a}$ and prothrombin was performed. The retinopathy grade was not associated with Gp2b3a where only 9 mutations were identified, hereof seven women with simplex retinopathy and two women without retinopathy ( 28 vs. $22 \%$, incidence of mutation in retinopathy $v s$. no retinopathy, $\mathrm{p}=1.0$ ). No mutations in prothrombin were found in the same 40 women. The birth weight ratio was similar with respect to any of the analyzed mutations.

\section{Discussion}

The retinopathy and AASI showed a strong association throughout pregnancy in women with type 1 diabetes indicating that increased arterial stiffness is, in fact, associated with the vasculopathy. This relationship was not found outside pregnancy. Our findings indicate that vascular resistance was more apparent during pregnancy in

Table 2. MTFHR- polymorphism in women with type 1 diabetes mellitus by retinopathy grade and in background population.

\begin{tabular}{|l|l|l|l|l|}
\hline \multicolumn{4}{|l|}{ MTFHR-Polymorphism } & \\
\hline Retinopathy grade & No & Heterozygosis & Homozygosis & All \\
\hline No & 46 & 63 & 12 & 121 \\
\hline Simplex & 38 & 47 & 7 & 92 \\
\hline Proliferative & 9 & 10 & 1 & 20 \\
\hline $\begin{array}{l}\text { All women with type } \\
1 \text { diabetes mellitus }\end{array}$ & 93 & 120 & 20 & 233 \\
\hline $\begin{array}{l}\text { Background } \\
\text { population }\end{array}$ & 542 & 455 & 87 & 1084 \\
\hline
\end{tabular}

women with type 1 diabetes than outside pregnancy. It appeared that some women with microangiopathy failed to respond to the physiological adaptations during pregnancy and this may be in part due to pre-existing structural features. Functionally impaired sensibility to circulating vasodilating mediators may theoretically play a role; this was not further investigated in this study.

We hypothesize that adaptation took place post partum, despite the relatively short time since delivery. Furthermore, the impact of lactation on vascular physiology and BP is not known. In concordance with our findings, others have shown that AASI is associated with retinopathy in non-pregnant patients with type 1 diabetes, including males $[24,25]$.

There are some weaknesses in our study, which was performed prospectively but obviously has difficulties in obtaining complete data on blood pressure at all time points. Nevertheless, the number of participants is rather high for the methodology applied but does not take into account the antihypertensive treatment of some of women. The clinical applicability, however, was little changed by this fact. Despite a few neglectors, the majority consented to participate in the study and could be more motivated to continue also after delivery, even in the most problematic cases. Some selection bias has occurred due to referral to our tertiary center. However, it is unlikely that the usefulness of AASI during pregnancy would be better displayed as few pregnancies have higher risk of blood pressure and microvascular disorders.

Vasodilatation during pregnancy influence retinopathy and may worsen its clinical course, in particular with concurrent glycemic malregulation $[2,26]$. This vasodilatation and stroke volume may also affect AASI, so one may argue that it is not reflecting stiffness of the vessels but rather pregnancy adaptation and regression post partum. In normal pregnancy changes in the arterial and venous sides of the circulation occur independently of pressure alterations with increase in

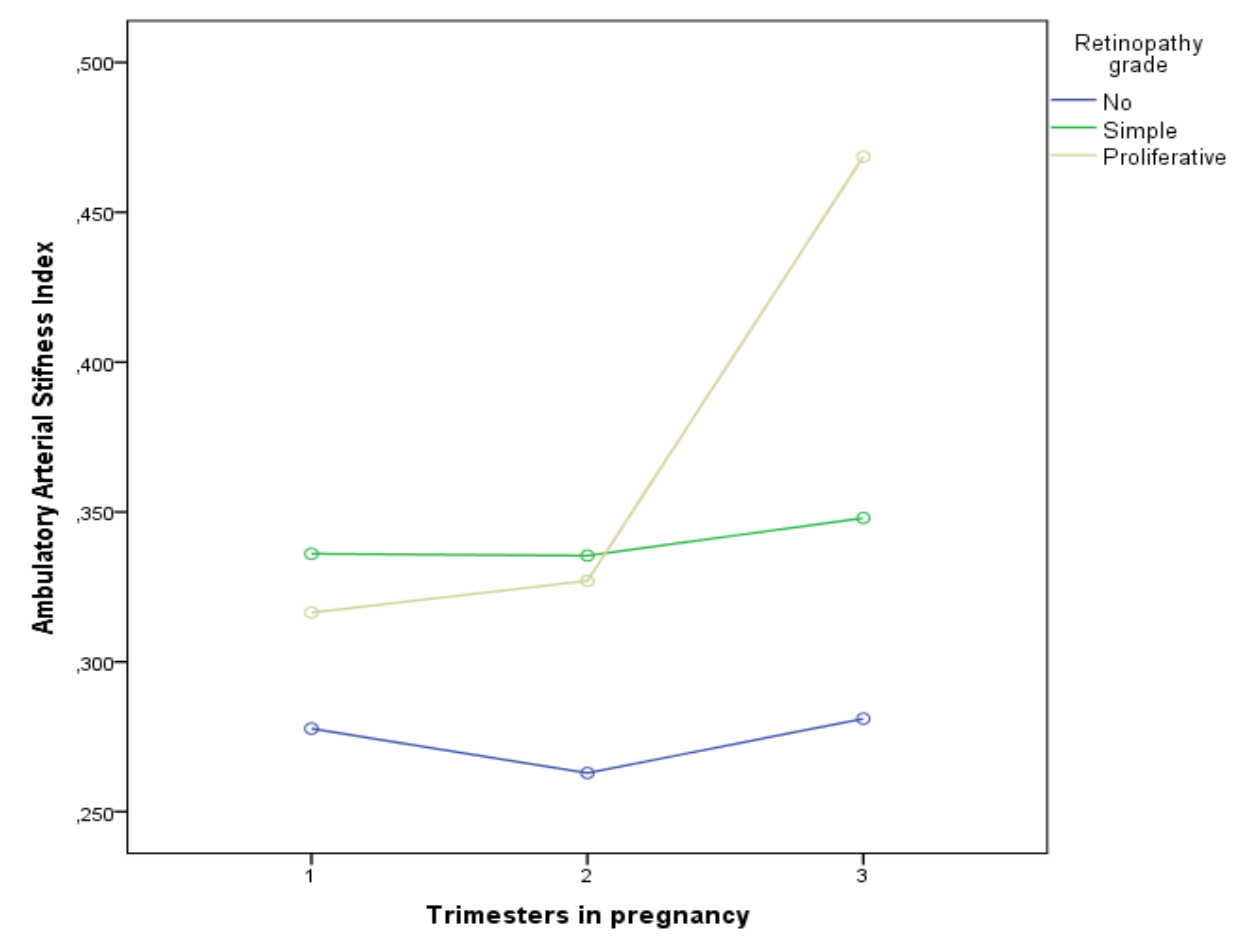

Covariates appearing in the model are evaluated at the following values: Aqe $=28.5, \mathrm{HbA} 1 \mathrm{c}=7.30, \mathrm{BMI}=24.57$

Figure 2. AASI during pregnancy by retinopathy grade. 
venous tone, i.e., preload, and decrease in aortic stiffness, thus reducing afterload, which tend to optimize cardiac function until delivery [27]. We confirm these observations in the changes in arterial stiffness from 3rd trimester to post partum but extend this to be associated with microangiopathy i.e. retinopathy. The findings are not likely biased by our selected high risk setting as the findings were adjusted for preeclampsia and glycemic regulation.

Another lesson to learn on the relation of retinopathy with AASI is displayed in Figure 1 as the mean level of blood pressure need not to be high in order to imply a high AASI. Nevertheless by inspection, the woman with proliferative retinopathy reveals a stiffer vascular bed and less linear relationship in the variation of blood pressure.

The cross-sectional design of the study did not measure plasma homocysteine and coagulation factor levels and thus precluded the observation of development of vascular complications with these variables. The sampling of the study population aimed at studying pregnancy-induced vascular manifestations that in non-pregnant population samples was associated with MTFHR polymorphism $[20,28,29]$. The lack of association may be in part due to variation of incidence of retinopathy and preeclampsia in different population rather than diagnostic criteria; in addition, other background genetic factors may still be involved [8]. Thus, ameliorating the proposed effects of hyperhomocysteinemia with folic acid, vitamin B6, and anticoagulants has proved inconclusive in prophylaxis on preeclampsia $[9,11,30]$.

The number of homozygotes of mutations in the MTFHR gene may be caused of either selection or random bias in a relative small sample like ours. Homozygosis number of a studied mutation maybe prone to ill-effects on health and complications associated with diabetes mellitus. These women may not have become pregnant at all and, thus, not entering our sample of pregnant, diabetic women. However, our observation of a perfect Hardy-Weinberg equilibrium does not support this view. The incidences of mutations in Gp2b3a and prothrombin are too low to explain common morbidity like retinopathy and preeclampsia. However, to our knowledge no similar study has been reported in pregnant, diabetic women.

In conclusion, retinopathy showed a strong association with AASI during pregnancy and not outside pregnancy in women with type 1 diabetes. This suggests a pregnancy-related functional change in the vascular bed.

\section{Acknowledgments}

The study was supported by a grant from M.C. and J.K. Moltum's Foundation.

\section{Contribution of authors}

FFL: Designed and performed the studies in the maternity ward, designed and wrote the manus.

PLG: Performed the mutation analysis, reviewed the ophthalmological examinations, wrote and discussed the manus.

HFMAF: Collected the data on blood pressure and AASI in the women. Discussed and edited the manus.

IHT: Collected the data on blood pressure and AASI in the women. Discussed and edited the manus.

OWR: Designed the studies on blood pressure in the maternity ward, wrote and discussed the manus.

\section{Ethics}

Local Ethical committee permissions: No. 1992/2523, 1998/4147, and 2026-99.

Danish Data Protection Agency permissions: No. 1-16-02-92-16).

\section{References}

1. Kaaja R (2011) Vascular complications in diabetic pregnancy. Thromb Res 127 Suppl 3: S53-55. [Crossref]

2. Lauszus FF, Klebe JG, Bek T, Flyvbjerg A (2003) Increased serum IGF-I during pregnancy is associated with progression of diabetic retinopathy. Diabetes 52: 852856. [Crossref]

3. Hofmann MA, Kohl B, Zumbach MS, Borcea V, Bierhaus A, et al. (1997) Hyperhomocyst(e)inemia and endothelial dysfunction in IDDM. Diabetes Care 20: 1880-1886. [Crossref]

4. Chico A, Perez A, Cordoba A, Arcelus R, Carreras G, et al. (1998) Plasma homocysteine is related to albumin excretion rate in patients with diabetes mellitus: a new link between diabetic nephropathy and cardiovascular disease? Diabetologia 41: 684-693.

5. Elias AN, Eng S (2005) Homocysteine concentrations in patients with diabetes mellitus--relationship to microvascular and macrovascular disease. Diabetes Obes Metab 7: 117-121. [Crossref]

6. Glueck CJ, Wang P, Bell H, Rangaraj V, Goldenberg N (2004) Nonarteritic anterior ischemic optic neuropathy: associations with homozygosity for the C677T methylenetetrahydrofolate reductase mutation. J Lab Clin Med 143:184-192. [Crossref]

7. Powers RW, Evans RW, Majors AK, Ojimba JI, Ness RB, et al. (1998) Plasma homocysteine concentration is increased in preeclampsia and is associated with evidence of endothelial activation. Am J Obstet Gynecol 179: 1605-1611. [Crossref]

8. Alfirevic Z, Roberts D, Martlew V (2002) How strong is the association between maternal thrombophilia and adverse pregnancy outcome? A systematic review. Eur $J$ Obstet Gynecol Reprod Biol 101: 6-14.

9. Leeda M, Riyazi N, de Vries JI, Jakobs C, van Geijn HP, et al. (1998) Effects of folic acid and vitamin B6 supplementation on women with hyperhomocysteinemia and a history of preeclampsia or fetal growth restriction. Am J Obstet Gynecol 179: 135-139. [Crossref]

10. Frosst P, Blom HJ, Milos R, Goyette P, Sheppard CA, et al. (1995) A candidate genetic risk factor for vascular disease: a common mutation in methylenetetrahydrofolate reductase. Nat Genet 10: 111-113. [Crossref]

11. Sohda S, Arinami T, Hamada H, Yamada N, Hamaguchi H, et al. (1997) Methylenetetrahydrofolate reductase polymorphism and pre-eclampsia. J Med Genet 34: 525-526. [Crossref]

12. Livrinova V, Lega MH, Dimcheva AH, Samardziski I, Isjanovska R (2015) Factor V Leiden, Prothrombin and MTHFR mutation in patients with preeclampsia, intrauterine growth restriction and placental abruption. Maced J Med Sci 3: 590-594. [Crossref]

13. Dudding T, Heron J, Thakkinstian A, Nurk E, Golding J, et al. (2008) Factor V Leiden is associated with pre-eclampsia but not with fetal growth restriction: a genetic association study and meta-analysis. J Thromb Haemost 6: 1869-1875. [Crossref]

14. Glueck CJ, Wang P (2009) Ocular vascular thrombotic events: a diagnostic window to familial thrombophilia (compound factor V Leiden and prothrombin gene heterozygosity) and thrombosis. Clin Appl Thromb Hemost 15: 12-18. [Crossref]

15. Mendez-Figueroa H, Davidson C (2010) Bilateral retinal detachments and preeclampsia: thrombotic thrombocytopenic purpura or syndrome of haemolysis, elevated liver enzymes, low platelets? J Matern Fetal Neonatal Med 23: 1268-1270. [Crossref]

16. O'Shaughnessy KM, Fu B, Downing S, Morris NH (2001) Morris Thrombophilic polymorphisms in pre-eclampsia: altered frequency of the functional $98 \mathrm{C}>\mathrm{T}$ polymorphism of glycoprotein IIIa. J Med Genet 38: 775-777. [Crossref]

17. O’Brien E, Asmar R, Beilin L, Imai Y, Mallion JM, et al. (2003) European Society of Hypertension Working Group on Blood Pressure Monitoring. European Society of Hypertension recommendations for conventional, ambulatory and home blood pressure measurement. J Hypertens 21: 821-848. [Crossref]

18. Dolan E, Li Y, Thijs L, McCormack P, Staessen JA, et al. (2006) Ambulatory arterial stiffness index: rationale and methodology. Blood Press Monit 11: 103-105. [Crossref]

19. Marsál K, Persson PH, Larsen T, Lilja H, Selbing A, et al. (1996) Intrauterine growth curves based on ultrasonically estimated foetal weights. Acta Paediatr 85: 843-848. [Crossref] 
20. Jinks DC, Minter M, Tarver DA, Vanderford M, Hejtmancik JF, et al. (1989) Molecular genetic diagnosis of sickle cell disease using dried blood specimens on blotters used for newborn screening. Hum Genet 81: 363-366. [Crossref]

21. Gaustadnes M, Rüdiger N, Möller J, Rasmussen K, Bjerregaard-Larsen T, et al. (1999) Thrombophilic predisposition in stroke and venous thromboembolism in Danish patients. Blood Coagul Fibrinolysis 10: 251-259. [Crossref]

22. Miller SA, Dykes DD, Polesky HF (1988) A simple salting out procedure for extracting DNA from human nucleated cells. Nucleic Acids Res 16: 1215. [Crossref]

23. Rodriguez-Fontal M, Kerrison JB, Alfaro DV, Jablon EP (2009) Metabolic control and diabetic retinopathy. Curr Diabetes Rev 5: 3-7. [Crossref]

24. Wilkinson IB, MacCallum H, Rooijmans DF, Murray GD, Cockcroft JR, et al. (2000) Increased augmentation index and systolic stress in type 1 diabetes mellitus. QJM 93: 441-448. [Crossref]

25. Ahlgren AR, Astrand H, Sundkvist G, Länne T (2005) Increased aortic stiffness is persistent in type 1 diabetic women: a follow-up study. Diabetologia 48: 780-783. [Crossref]

26. O'Connor F, Fitzgerald DJ, Murphy RP (2000) An automated heteroduplex assay for the PlA polymorphism of glycoprotein IIb/IIIa, multiplexed with two prothrombotic genetic markers, factor V Leiden, and methylenetetrahyrofolate reductase. Throm Haem 83: 248-252. [Crossref]

27. Pandey AK, Siwach S, Sangwan V, Sharma S, Das A (2014) Assessment of maternal vascular stiffness indices in three trimesters of normal pregnancy. Indian $J$ Physiol Pharmacol 58: 197-205. [Crossref]

28. Aruda VR, von Zuben PM, Chiaparini LC, Annichino-Bizzachi JM, Costa FF (1997) The mutation Ala677-->Val in the methylene tetrahydrofolate reductase gene: a risk factor for arterial disease and venous thrombosis. Thromb Haemost 77: 818-821. [Crossref]

29. Catteneo M, Tsai MY, Bucciarelli P, Taioli E, Zighetti ML, et al. (1997) A common mutation in the methylenetetrahydrofolate reductase gene (C677T) increases the risk for deep-vein thrombosis in patients with mutant factor V (Factor V:Q (506)) Arterioscler Thromb Vasc Biol 17: 1662-1666. [Crossref]

30. Moore GS, Allshouse AA, Post AL, Galan HL, Heyborne KD (2015) Early initiation of low-dose aspirin for reduction in preeclampsia risk in high-risk women: a secondary analysis of the MFMU High-Risk Aspirin Study. J Perinatol 35: 328-331. [Crossref]

Copyright: $₫ 2017$ Lauszus FF. This is an open-access article distributed under the terms of the Creative Commons Attribution License, which permits unrestricted use, distribution, and reproduction in any medium, provided the original author and source are credited. 